\title{
The evolving role of zoledronic acid in early breast cancer
}

This article was published in the following Dove Press journal:

OncoTargets and Therapy

24 April 2009

Number of times this article has been viewed

\section{Michael Gnant \\ Department of Surgery, Medical University of Vienna, Vienna, Austria}

Correspondence: Michael Gnant Department of Surgery, Medical University of Vienna,Währinger Gürtel 18-20, A-1090Vienna, Austria

Tel +43 | 404005646

$\mathrm{Fax}+43$ | 404006807

Email michael.gnant@meduniwien.ac.at

\begin{abstract}
Most women with early breast cancer (BC) have an excellent prognosis and will remain disease-free for many years after treatment. However, bone-specific side effects of cancer therapies can have a negative effect on patients' long-term bone health. The accelerated bone loss associated with BC therapies, especially endocrine therapy, can put women at risk for osteoporosis and fractures later in life. Recent treatment guidelines have now begun to address the need for bone-preserving measures to be included in adjuvant therapy regimens. Bisphosphonates have long been used to treat osteoporosis, as well as bone metastases in patients with advanced cancers. Furthermore, in the adjuvant BC setting, the intravenous bisphosphonate zoledronic acid has emerged to play an important role. Several large, randomized phase III trials involving a total of approximately 4,000 premenopausal and postmenopausal women with early BC demonstrated the bone-protective effects of adjuvant zoledronic acid (4 mg every 6 months). Additionally, these same trials also showed significant improvement in disease-free survival for patients receiving adjuvant endocrine therapy plus zoledronic acid that was over and above the benefit achieved with endocrine therapy alone. The results of these zoledronic acid trials will be reviewed herein, and evidence supporting the antitumor effects of adjuvant zoledronic acid will be discussed.
\end{abstract}

Keywords: breast cancer, bisphosphonate, adjuvant therapy, antitumor, BMD, fracture risk

\section{Introduction}

Improvements in screening and public awareness in industrialized nations have resulted in the majority of breast cancers being diagnosed at an early stage. ${ }^{1}$ Because most patients with early breast cancer will survive for many years, managing the negative side effects of long-term cancer therapies is important for preserving patients' quality of life (QOL). For example, known side effects of many breast cancer therapies include reduced bone mineral density (BMD) and diminished bone quality and microarchitecture, both of which contribute to increased risk of fracture in women with breast cancer. ${ }^{2,3}$ Chemotherapy can have a direct negative effect on bone-producing cells (osteoblasts), and can also cause ovarian failure and premature menopause in premenopausal patients. ${ }^{4,5}$ For example, a chart review of 130 postmenopausal patients who received chemotherapy for breast cancer demonstrated that their age-adjusted BMD was at least 0.5 standard deviations below those of the group that did not receive chemotherapy (a decrease that may be equated with a $40 \%$ increased risk of fracture). ${ }^{4}$ In premenopausal patients who developed chemotherapy-induced ovarian failure there was significant BMD loss in the spine at both 6 and 12 months compared with patients who did not lose ovarian function ( $\mathrm{p}=0.0001$ for both) ${ }^{5}$ 
Because the majority of breast cancers are hormone responsive, ${ }^{6}$ endocrine therapy has become the treatment of choice in these patients. However, because endocrine therapy reduces estrogen levels, it is also associated with rapid bone loss in both pre- and postmenopausal women. ${ }^{7-12}$ Several clinical trials in postmenopausal women with early breast cancer demonstrated significant increases in bone loss and fracture incidence in patients receiving both steroidal and nonsteroidal aromatase-inhibitor therapy. ${ }^{7,810-12}$ For example, in the Arimidex $^{\circledR}$, Tamoxifen, Alone or in Combination (ATAC) trial $(\mathrm{N}=6186)$, patients receiving anastrozole experienced significantly more fractures $(11 \%)$ compared with patients receiving tamoxifen $(7.7 \%$; $<<0.0001) .{ }^{10}$ The increased fracture rate may be explained by the rapid bone loss observed in patients receiving anastrozole in the bone substudy of this trial. Within 2 years of beginning therapy, patients receiving anastrozole had lost approximately $4 \%$ BMD at both the lumbar spine and total hip compared with baseline $(\mathrm{p}<0.001$ for both), ${ }^{8}$ and after 5 years the anastrozole group had lost $6.08 \%$ and $7.24 \%$ BMD at the lumbar spine and hip, respectively ( $p<0.0001$ for both compared with tamoxifen). ${ }^{13}$ Similarly, in the Breast International Group (BIG) 1-98 trial $(\mathrm{N}=8010)$, postmenopausal women with early breast cancer receiving letrozole experienced significantly more fractures than patients receiving tamoxifen $(5.7 \%$ versus $4.0 \%$, respectively; $<<0.001$ ). ${ }^{12}$ In the Intergroup Exemestane Study (IES; $\mathrm{N}=4724$ ) after 2 to 3 years of tamoxifen therapy, patients receiving exemestane lost approximately $3 \%$ in lumbar spine BMD and fracture incidence was significantly higher compared with those who continued to receive tamoxifen $(7.0 \%$ versus $4.9 \% ; \mathrm{p}=0.003){ }^{7,14}$ Results from these trials and others indicate that women with breast cancer receiving endocrine therapy are at increased risk for fracture.

Major determinants of a woman's lifetime fracture risk include peak bone mass at maturity and rate of bone loss later in life. ${ }^{15}$ Therefore, not only does natural bone loss after menopause contribute to fracture risk, but any cancer therapy that prematurely decreases BMD can further increase a patient's fracture risk. As a result, clinical guidelines have been developed for managing bone health issues in breast cancer patients. Early guidelines to address bone health issues in patients with breast cancer, like those used to guide treatment for postmenopausal osteoporosis, ${ }^{15,16}$ relied on BMD as the primary indicator of treatment (ie, T-score $\leq-2.5) .{ }^{17}$ However, newer recommendations have evolved that can be used to assess a patient's fracture risk based on clinical risk factors with or without the addition of BMD measurements. ${ }^{18-20}$
Therapy to prevent treatment-associated bone loss in women with breast cancer has evolved alongside improvements in endocrine therapy. Oral bisphosphonates have demonstrated some efficacy in this setting. In 1 small trial in premenopausal women with chemotherapy-induced ovarian failure $(\mathrm{N}=73)$, oral clodronate slowed but did not prevent bone loss. ${ }^{21}$ Two small studies in postmenopausal women receiving anastrozole showed that weekly risedronate $(\mathrm{N}=234)$ and monthly ibandronate $(\mathrm{n}=50)$ increased $\mathrm{BMD}$ at the lumbar spine and hip in patients with osteopenia at baseline. ${ }^{22,23}$ In the adjuvant therapy setting, zoledronic acid has demonstrated significant efficacy for prevention of treatment-associated bone loss in women with early breast cancer. In several large, phase III trials, which included a total of 3996 patients, zoledronic acid (4 mg every 6 months) improved BMD in pre- and postmenopausal women receiving adjuvant endocrine therapy for early breast cancer., ${ }^{94-26}$ In addition to the bone health benefits of zoledronic acid, preclinical evidence and recent clinical data have revealed that zoledronic acid has significant antitumor activity that extends beyond bone (ie, induction of tumor cell apoptosis; inhibition of tumor cell adhesion, invasion, and proliferation; synergy with chemotherapy; and activation of the immune system). ${ }^{27-38}$ As evidenced by data from preclinical studies, zoledronic acid can interfere with many of the steps necessary for tumor metastasis, which may explain the clinical benefits observed with zoledronic acid in clinical trials (Figure 1). ${ }^{39}$ This review will compare current and emerging guidelines for managing bone health in breast cancer survivors, examine the evidence for using zoledronic acid in preventing cancer treatment-induced bone loss (CTIBL), and review the recent results that demonstrate the antitumor effects of zoledronic acid in the clinical setting.

\section{Assessing guidelines for managing bone health in women with breast cancer}

Historically, clinical guidelines for managing bone health in women with breast cancer have relied on BMD measurements to guide pharmacologic intervention. For example, the 2003 American Society of Clinical Oncology (ASCO) guidelines recommended bisphosphonate therapy only when BMD T-scores fall into the osteoporotic range (T-score $\leq-2.5) .{ }^{17}$ However, evidence from a variety of clinical trials has since clearly demonstrated that patients have significantly increased fracture risk long before becoming osteoporotic. In the National Osteoporosis Risk Assessment (NORA) study of healthy postmenopausal women between 50 and 104 years of age 
Direct antitumor effect

Indirect antitumor effect

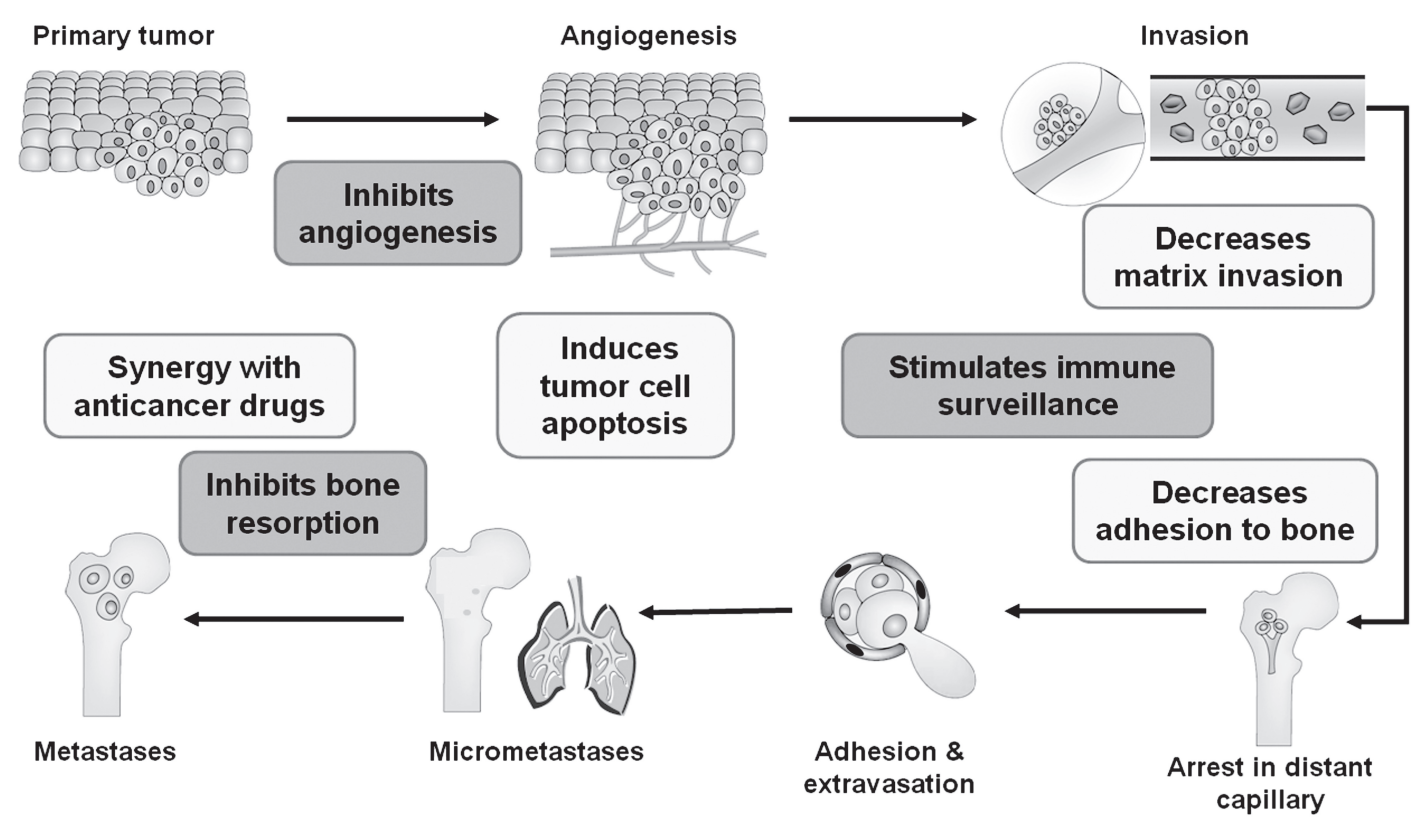

Figure I Antitumor effects of zoledronic acid that may contribute to improved disease-free survival in the adjuvant therapy setting. Adapted by permission from Macmillan Publishers Ltd. Mundy GR, et al. Nat Rev Cancer. 2002;2(8):584-593. ${ }^{39}$ Copyright @ 2002.

$(\mathrm{N}=149,524$; mean age 64.5 years), the majority of fractures $(82 \%)$ occurred in women who had normal (T-score $\geq-1.0)$ or osteopenic BMD (T-score between -1.0 and -2.5$).{ }^{40}$ This suggests that fracture risk increases long before a woman's BMD reaches the clinical definition of osteoporosis (T score $\leq-2.5$ ).

Beyond the influence of BMD on fracture risk, a number of clinical risk factors have been shown to contribute to fracture risk independently of BMD in postmenopausal women. ${ }^{41}$ In fact, a recent systematic review of published literature found that many of the clinical risk factors for fracture (with and without BMD) can be used to assess fracture risk and guide treatment decisions in women with breast cancer. ${ }^{20}$ After critical review of the published literature, the authors recommended intervention with bisphosphonate therapy (eg, zoledronic acid $4 \mathrm{mg}$ every 6 months) for women with breast cancer initiating or receiving aromatase inhibitor therapy who have any 2 of the following risk factors: T-score $<-1.5$, age $>65$ years, low body mass index $\left(\mathrm{BMI} ;<20 \mathrm{~kg} / \mathrm{m}^{2}\right)$, family history of hip fracture, personal history of fragility fracture after age 50, oral corticosteroid use $>6$ months, and smoking (Figure 2). ${ }^{20}$ Recently, the Fracture Risk Assessment Tool $\left(\right.$ FRAX $^{\circledR}$ ), a Web-based algorithm, was developed by the World Health Organization (WHO) to evaluate patient fracture risk, and is based on individual patient models that integrate the risks associated with clinical risk factors and femoral-neck BMD. ${ }^{18}$ The FRAX computer algorithms give the 10 -year probability of hip fracture or any major osteoporotic fracture (clinical spine, forearm, hip, or shoulder). This tool takes into consideration several independent risk factors to assess fracture risk and can be used with or without BMD evaluations. Because the FRAX tool was designed to evaluate fracture risk in healthy women, it does not include the risks associated with chemotherapy, ovarian suppression/ablation, or endocrine therapy, and therefore it will likely underestimate the fracture risk in patients with breast cancer. Therefore, overall fracture risk assessment may include the FRAX tool, but should also include cancer-specific guidelines that take into account the contribution of cancer therapies. Overall, these treatment recommendations and fracture risk evaluation tools emphasize the importance of a comprehensive fracture-risk assessment and may help to identify women who will benefit from early intervention, especially in the early breast cancer setting.

\section{Zoledronic acid for preventing bone loss during cancer therapy}

It is clear that a patient's overall fracture risk is a function of both BMD and clinical risk factors, and preventing bone loss has been shown to reduce long-term fracture risk. In the 


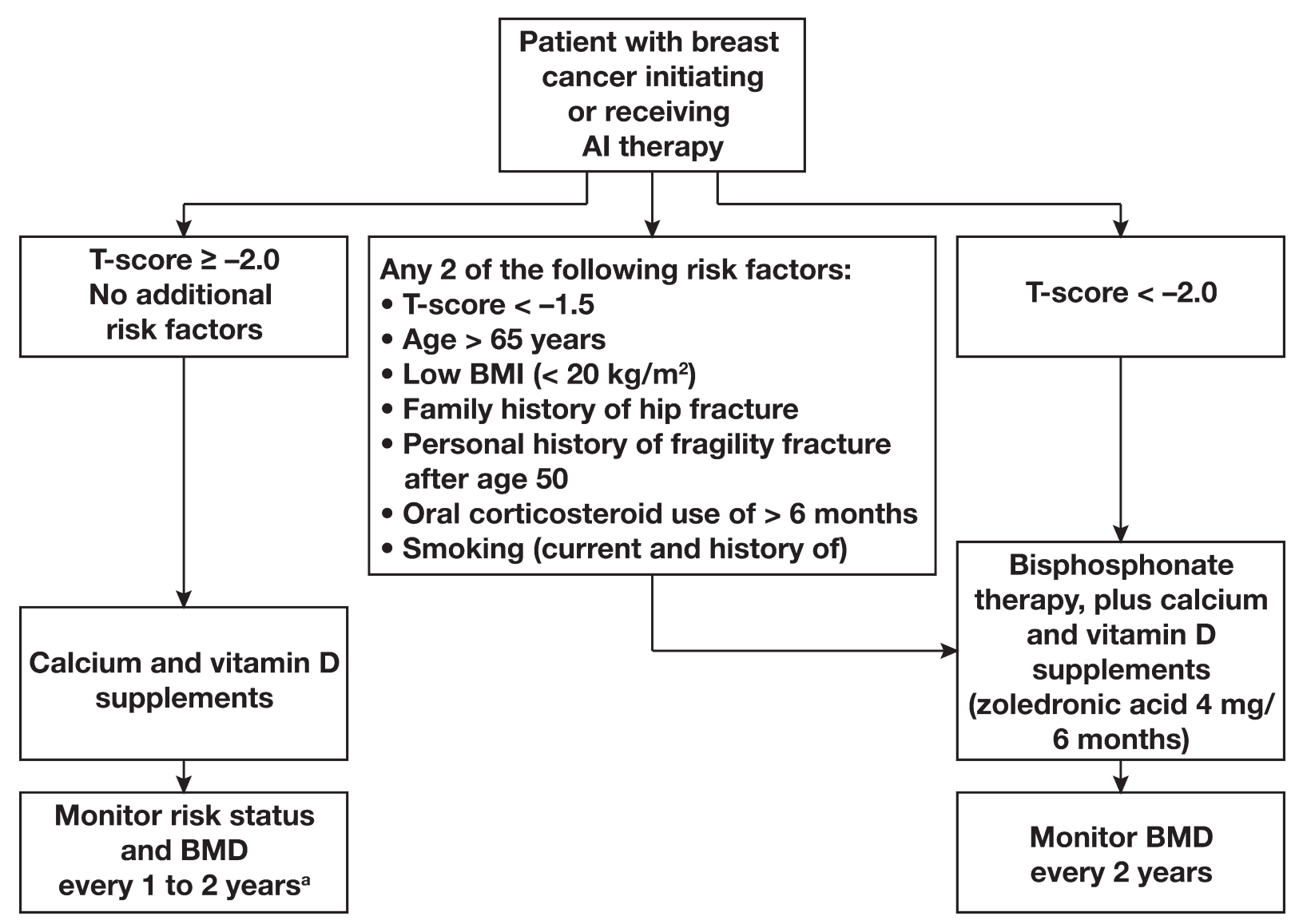

Figure 2 Management recommendations for patients with breast cancer receiving aromatase inhibitor (Al) therapy, based on results from breast cancer trials in patients and healthy controls. alf patients experience annual decrease in bone mineral density (BMD) of $\geq 5 \%$ (using the same imaging machine), secondary causes of bone loss such as vitamin $\mathrm{D}$ deficiency should be evaluated and bisphosphonate therapy considered. Use lowest T-score from 3 sites. Adapted from Hadji P, et al. Practical guidance for the management of aromatase inhibitor-associated bone loss. Ann Oncol. 2008;19(8): 1407-1416 ${ }^{20}$ by permission of Oxford University Press.

Abbreviation: BMI, body mass index.

setting of postmenopausal osteoporosis, bisphosphonates have long been used to prevent and reverse age-related bone loss. The nitrogen-containing bisphosphonate zoledronic acid inhibits osteoclast-mediated bone resorption and has been approved to treat postmenopausal osteoporosis and to prevent skeletal-related events (SREs) associated with bone metastases from advanced breast cancer and other solid tumors. ${ }^{42,43}$

More recently, zoledronic acid (4 mg intravenously every 6 months) demonstrated significant bone-protective effects in the Austrian Breast and Colorectal Cancer Study Group Trial 12 (ABCSG-12; N = 1803) in premenopausal women with early hormone-responsive breast cancer receiving adjuvant endocrine therapy. The bone substudy of ABCSG-12 $(n=404)$ focused on the effect of zoledronic acid on BMD during endocrine therapy. ${ }^{44}$ Patients who received endocrine therapy alone (goserelin plus tamoxifen or goserelin plus anastrozole) had significant bone loss during 3 years of therapy, resulting in an overall $14.4 \%$ loss from baseline
( $p<0.0001)$. In the same study, patients who received endocrine therapy plus zoledronic acid maintained stable BMD during the 3 years of treatment. Furthermore, after a median follow-up of 60 months (2 years after completing therapy), patients who had received endocrine therapy alone still had BMD below baseline levels (Figure 3 ). ${ }^{9}$ In contrast, patients who had received endocrine therapy plus zoledronic acid during the same period had significantly improved BMD compared with baseline, suggesting that zoledronic acid continues to improve BMD even after treatment completion.

Several other phase III studies of zoledronic acid (4 mg intravenously every 6 months) have also demonstrated significant bone-protective effects during endocrine therapy for early breast cancer. The Zometa ${ }^{\circledR}$-Femara ${ }^{\circledR}$ Adjuvant Synergy Trials (Z-FAST, ZO-FAST, and E-ZO-FAST) compared upfront versus delayed zoledronic acid in 2194 postmenopausal women with early breast cancer receiving adjuvant letrozole. Patients in the upfront group received zoledronic acid concurrently with letrozole, and those in the delayed 
No zoledronic acid

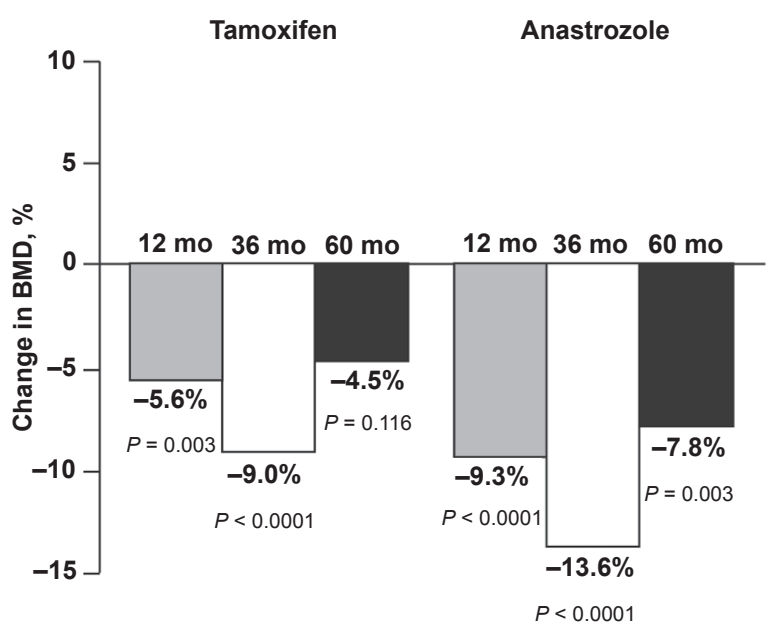

Zoledronic acid

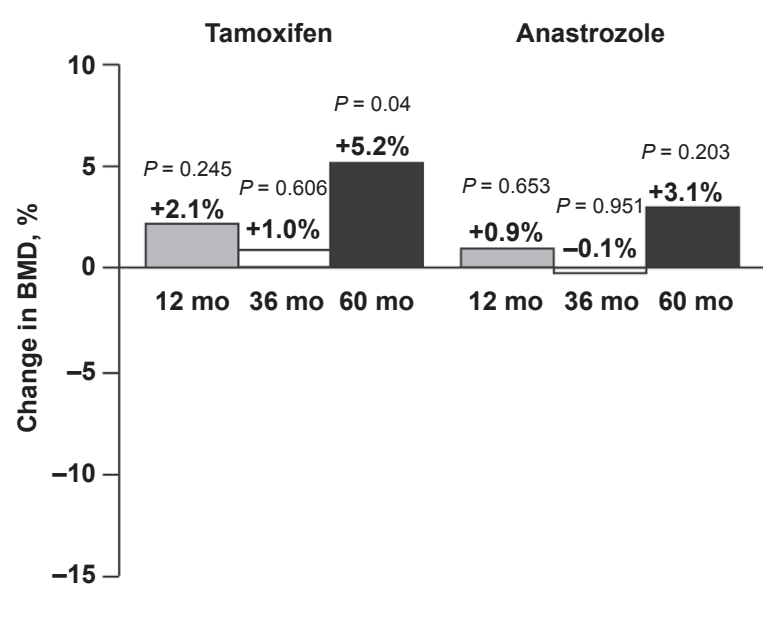

Figure 3 Zoledronic acid improves bone mineral density (BMD) from baseline to 60 months during adjuvant endocrine therapy. Patients were randomly assigned to anastrozole or tamoxifen \pm zoledronic acid (4 mg every 6 months) for 36 months, then no treatment from 36 to 60 months. P values were calculated using 2 -sample $t$-tests for mean differences from baseline. Reprinted from Lancet Oncol, Vol 9, Gnant M, et al. Adjuvant endocrine therapy plus zoledronic acid in premenopausal women with early-stage breast cancer: 5-year follow-up of the ABCSG-12 bone-mineral density substudy, p. 840-849. ${ }^{9}$ Copyright (C) 2008, with permission from Elsevier.

group received zoledronic acid only after a postbaseline BMD $\mathrm{T}$-score $\leq-2.0$ or after experiencing a nontraumatic fracture. After a median follow-up of 36 months in the Z-FAST trial $(\mathrm{N}=602)$, patients in the upfront zoledronic acid group had improved BMD compared with baseline, and those in the delayed group had lost BMD, resulting in a significant $6.7 \%$ difference in lumbar spine BMD between the upfront and delayed groups $(\mathrm{p}<0.0001) .{ }^{45}$ Similar bone-protective effects of upfront versus delayed zoledronic acid were seen after 36 months in the ZO-FAST trial $(9.3 \%$ difference in lumbar spine BMD, $\mathrm{p}<0.0001 ; \mathrm{N}=1065),{ }^{46}$ and after 12 months in the E-ZO-FAST trial (5.4\% difference in lumbar spine BMD, $\mathrm{p}<0.0001 ; \mathrm{N}=527) .{ }^{26}$ Although these trials were not designed or powered to assess differences in fracture rates between groups, there was a trend toward fewer fractures for upfront versus delayed zoledronic acid (2.9\% versus $3.7 \%$; hazard ratio $[\mathrm{HR}]=0.78 ; \mathrm{p}=0.34$ for all 3 trials combined).

Chemotherapy-induced premature menopause can increase the rate of bone loss, decreasing BMD and increasing a patient's long-term risk of osteoporosis and fracture. ${ }^{5}$ In 2 pilot studies $(\mathrm{N}=120 ; \mathrm{N}=101)$, zoledronic acid prevented bone loss associated with adjuvant chemotherapy in premenopausal women. ${ }^{47,48}$ In contrast with the established zoledronic acid dose (4 mg every 6 months) used in the adjuvant endocrine therapy setting (eg, ABCSG-12 and Z-FAST), the frequency of zoledronic acid dosing has not been standardized in the adjuvant chemotherapy setting. In 1 randomized phase II trial, 120 premenopausal and postmenopausal patients with stage II or III breast cancer received chemotherapy (epirubicin and docetaxel, both $75 \mathrm{mg} / \mathrm{m}^{2}$ ) plus concurrent zoledronic acid (4 mg every 3 weeks) or placebo for 1 year. ${ }^{47}$ After 1 year, both premenopausal and postmenopausal patients who received zoledronic acid had maintained stable BMD at all sites tested. During the same period, patients who received chemotherapy without zoledronic acid had significant BMD loss at the hip $(-4.5 \% ; \mathrm{p}<0.0001)$ and nonsignificant BMD loss at the spine $(-2.7 \% ; \mathrm{p}=0.057)$. Overall, premenopausal patients had the greatest loss of BMD at both sites $(-5.9 \% ; \mathrm{p}=0.0004$ at the hip, and $-5.7 \% ; \mathrm{p}=0.0167$ at the spine). In another randomized, double-blinded, 1-year, phase III trial in 101 premenopausal women with early breast cancer receiving adjuvant chemotherapy, zoledronic acid (4 mg every 3 months) also prevented bone loss. ${ }^{48}$ After 1 year, the BMD of placebo-treated patients had significantly decreased by $4.4 \%$ at the lumbar spine ( $p=0.0001)$, and by $2.1 \%$ at the total hip $(\mathrm{p}=0.02)$ compared with baseline (Figure 4). ${ }^{48}$ During the same period, zoledronic acid-treated patients maintained stable BMD compared with baseline (Figure 4). ${ }^{48}$ Taken together, the available evidence indicates that zoledronic acid effectively prevents bone loss associated with breast cancer therapies in both premenopausal and postmenopausal patients.

\section{Emerging evidence for prevention of disease recurrence with adjuvant zoledronic acid}

In addition to its bone-protective effects, zoledronic acid has also demonstrated antitumor properties in the adjuvant setting. In the main analysis of ABCSG-12 ( $\mathrm{N}=1803)$, 
premenopausal patients who received zoledronic acid had a $36 \%$ relative reduction in the risk of disease progression $(\mathrm{HR}=0.64 ; 95 \%$ confidence interval $[\mathrm{CI}]=0.46,0.91$; $\mathrm{p}=0.01$ ) compared with endocrine therapy alone (Figure 5). ${ }^{49}$ Notably, reductions in disease recurrence were observed at all sites (ie, contralateral breast cancer, locoregional recurrence, visceral metastases, and bone metastases), and were not limited to bone. However, at 47.8 months' median followup, the addition of zoledronic acid did not significantly reduce the risk of death $(\mathrm{HR}=0.60 ; 95 \% \mathrm{CI}=0.32,1.11$; $\mathrm{p}=0.11$ ); further follow-up is planned to determine whether differences in survival between groups will reach statistical significance at later timepoints. In the multivariate analyses, which estimate the effects of baseline variables (eg, age, tumor stage) on the relative risk of an event, zoledronic acid-treated patients had a significant 33\% relative reduction in the risk of disease progression $(\mathrm{HR}=0.67 ; \mathrm{p}=0.02)$ compared with no zoledronic acid. In the same analysis, the relative risk of disease progression was significantly increased by 1.5 - to 2.1 -fold for patients with $\geq \mathrm{T} 2$ or grade 3 or 4 tumors or lymph node involvement ( $p<0.05$ for all), although high progesterone-receptor expression was associated with significantly reduced risk of disease progression $(\mathrm{HR}=0.50 ; \mathrm{p}=0.001)$.
Zoledronic acid also appears to have antitumor properties in postmenopausal patients receiving adjuvant endocrine therapy. In a 12-month integrated analysis of the Z-FAST and ZO-FAST trials $(\mathrm{N}=1667)$, disease recurrence was significantly less frequent in patients who received upfront zoledronic acid compared with the delayed zoledronic acid group $(0.84 \%$ versus $1.9 \%$, respectively; $p=0.0401) .{ }^{24}$ After longer followup (24 months), results from the integrated analysis demonstrated a significant $43 \%$ improvement in disease-free survival (DFS) with upfront zoledronic acid $(\mathrm{HR}=0.573 ; \mathrm{p}=0.0183) .{ }^{50}$ Similarly, at 36 months' median follow-up in the ZO-FAST trial $(\mathrm{N}=1065)$, upfront zoledronic acid significantly improved DFS by a relative $41 \%(\mathrm{HR}=0.588 ; \mathrm{p}=0.0314) .{ }^{46}$ Taken together, the results from trials in both premenopausal and postmenopausal patients with early breast cancer indicate that adding zoledronic acid (4 mg every 6 months) to adjuvant endocrine therapy not only prevents therapy-associated bone loss, but can also significantly improve DFS.

Zoledronic acid (4 mg every 6 months) was well tolerated in patients receiving adjuvant endocrine therapy, with transient infusion-site reaction and mild flu-like symptoms (arthralgia and pyrexia) being the most common adverse events. ${ }^{26,45,46,49}$ Among the 4 phase III trials, osteonecrosis of the jaw (ONJ) was suspected in 6 of 3998 patients; however,

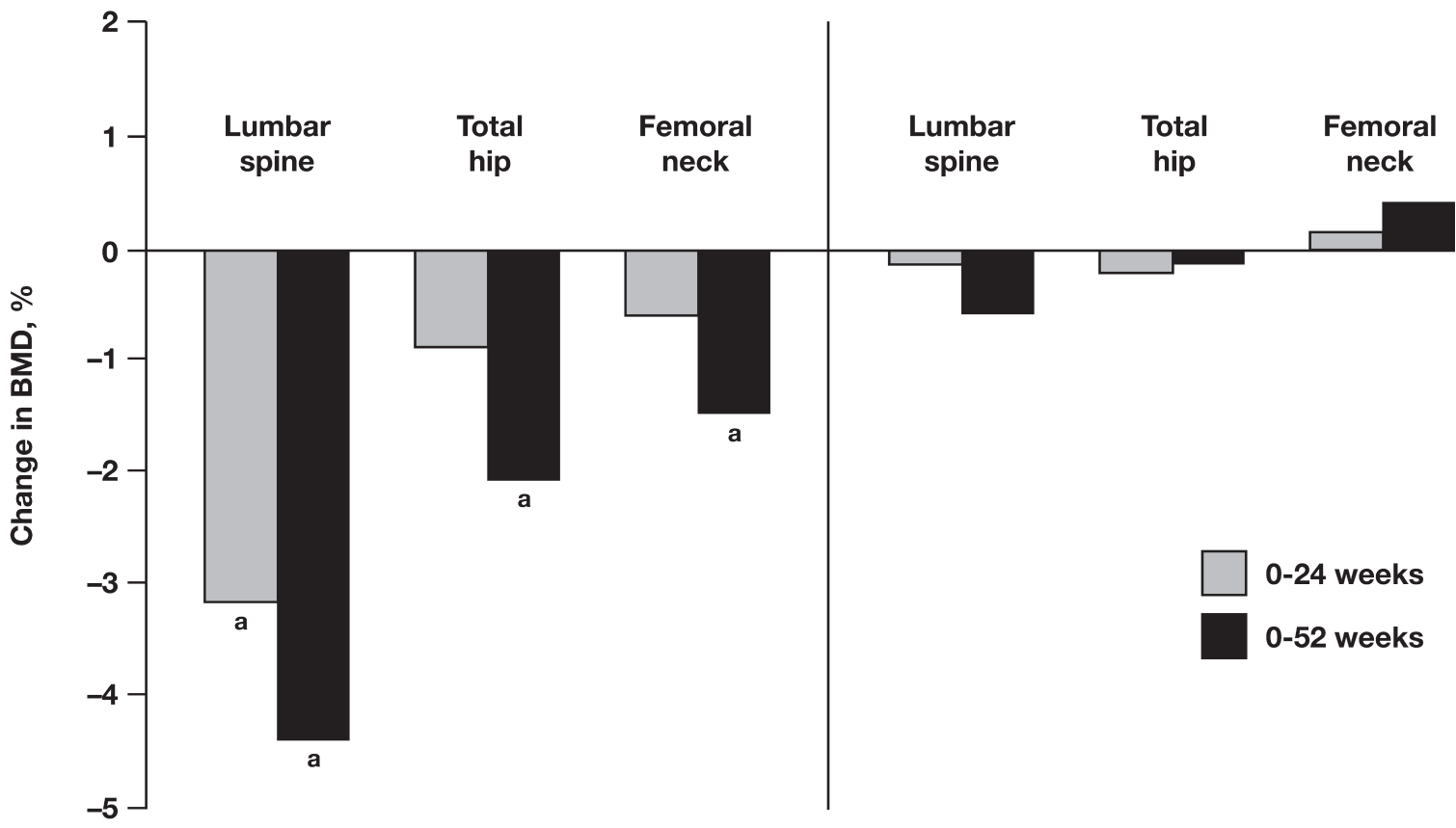

Placebo

Zoledronic acid

Figure 4 Zoledronic acid prevents chemotherapy-associated bone loss in premenopausal women. Shown are percentage changes in lumbar spine, total hip, and femoral neck bone mineral density (BMD) from baseline to 6 and 12 months. Patients were randomly assigned to chemotherapy plus zoledronic acid (4 mg every 3 months) or placebo for 12 months. ${ }^{a} \mathrm{p}<0.00 \mathrm{I}$ (between group). P values were calculated using 2-sample $t$-tests for mean differences from baseline. Hershman DL, et al.J Clin Oncol. 2008; 26(29):4739-4745. ${ }^{48}$ Reprinted with permission. (C) 2008 American Society of Clinical Oncology. All rights reserved. 


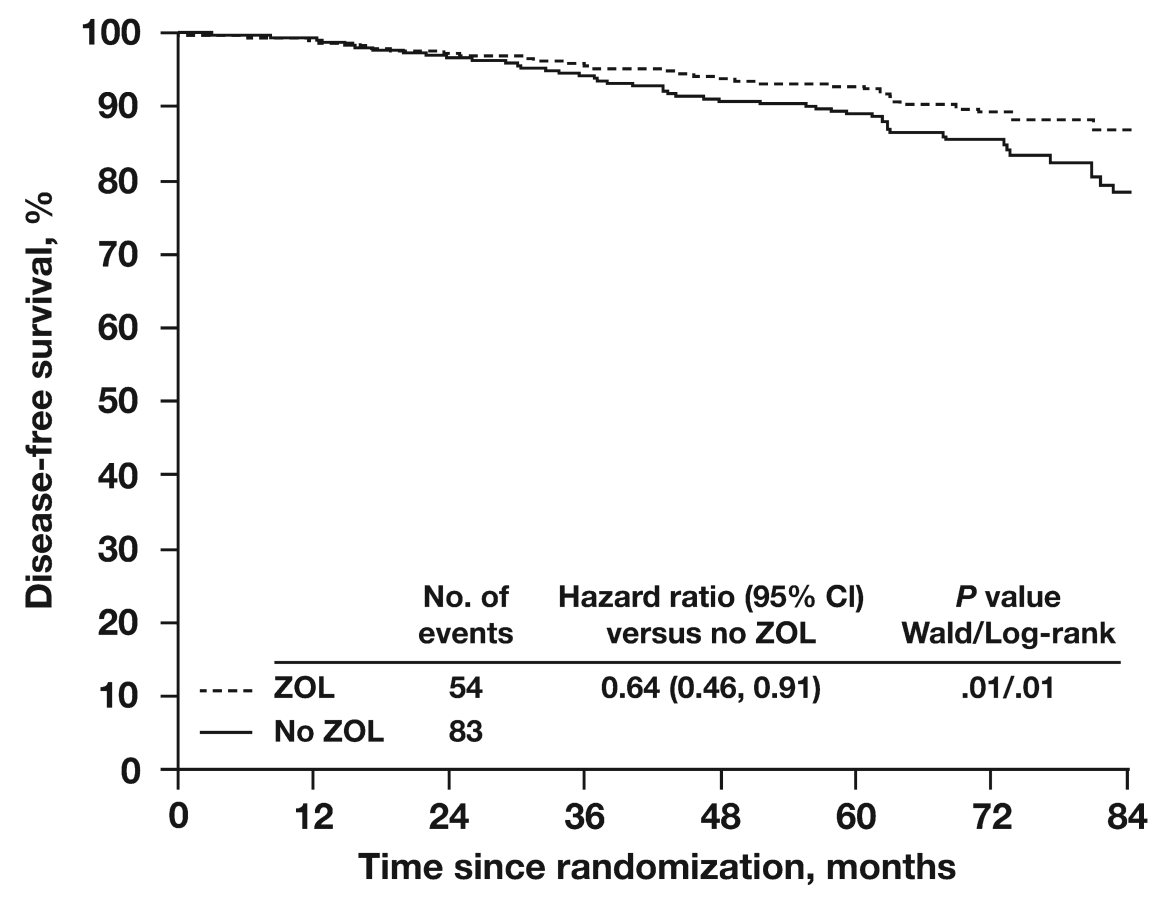

Number of patients at risk

$\begin{array}{ccccccccc}\text { ZOL } & 899 & 846 & 730 & 555 & 414 & 257 & 123 & 54 \\ \text { No ZOL } & 904 & 832 & 713 & 537 & 407 & 241 & 145 & 47\end{array}$

Figure 5 Disease-free survival in premenopausal patients with early breast cancer receiving adjuvant endocrine therapy plus zoledronic acid. Kaplan-Meier plots of disease-free survival are shown for women with breast cancer who received adjuvant endocrine therapy with or without zoledronic acid (ZOL versus No ZOL). ZOL denotes anastrozole/ goserelin and tamoxifen/goserelin plus zoledronic acid; No ZOL denotes anastrozole/goserelin and tamoxifen/goserelin without zoledronic acid. Adapted with permission from Gnant M, Mlineritsch B, Schippinger W, et al. Endocrine therapy plus zoledronic acid in premenopausal breast cancer. N Engl J Med. 2009;360(7):679-69I.49 Copyright @) 2009 Massachusetts Medical Society. All rights reserved.

only 1 case $(<0.05 \%)$ has been confirmed by the ONJ Adjudication Committee. ${ }^{26,45,46,49}$ In the same 4 trials, only 3 patients were suspected to have renal function impairment related to bisphosphonate treatment. ${ }^{26,45,46,49}$ In the adjuvant therapy setting, adverse events related to bisphosphonate therapy are mild and easily manageable, and the risk of rare adverse events can be further reduced with preventive measures and proper patient surveillance..$^{51,52}$

\section{Discussion}

Historically, bisphosphonates have been used to treat patients with advanced breast cancer and bone metastases, and have been shown to reduce SREs in clinical trials. ${ }^{53}$ For example, in patients with bone metastases from breast cancer, bisphosphonates reduced the proportion of patients who experienced SREs compared with placebo in phase III trials of pamidronate $(\mathrm{N}=754 ; \mathrm{p}<0.001),{ }^{54}$ ibandronate $(\mathrm{N}=466$; $\mathrm{p}=0.052),{ }^{55}$ and zoledronic acid $(\mathrm{N}=228 ; \mathrm{p}=0.003) .{ }^{56}$ However, the role of bisphosphonates may now expand to include protection of bone health in patients with early breast cancer receiving adjuvant endocrine therapy. Recent clinical trials have shown that bisphosphonates can prevent aromatase inhibitor-associated bone loss (AIBL) in postmenopausal patients receiving adjuvant endocrine therapy. ${ }^{22,25,26,57}$ Likewise, premenopausal patients with early breast cancer receiving adjuvant endocrine therapy can also benefit from the bone-protective effects of zoledronic acid. ${ }^{9}$

Recent evidence from clinical trials suggests that, in addition to its bone-preserving properties during adjuvant therapy, zoledronic acid's antitumor properties may reduce disease recurrence when it is combined with adjuvant endocrine therapy. Although the mechanism of zoledronic acid-mediated inhibition of CTIBL depends on inhibition of osteoclastmediated bone resorption, the mechanisms underlying the significant improvements in DFS observed in premenopausal and postmenopausal patients with early breast cancer are likely to be multifactorial. In ABCSG-12, patients receiving endocrine therapy plus zoledronic acid experienced fewer disease events (disease recurrence or death) than those receiving endocrine therapy alone. In this setting, zoledronic acid not only reduced the number of patients with bone metastases, but also reduced distant recurrence, locoregional recurrence, 
and contralateral breast cancer. ${ }^{49}$ Reductions in locoregional and distant recurrences (including bone) were also observed in postmenopausal patients who received upfront zoledronic acid combined with letrozole in the ZO-FAST study. ${ }^{46}$ These data suggest that zoledronic acid may improve DFS by exerting antitumor effects both within and outside of bone.

Interestingly, improved DFS with bisphosphonate treatment has been previously reported. ${ }^{58}$ The risk of bone metastases was reduced in patients with breast cancer who received oral clodronate for 2 years compared with no clodronate $(\mathrm{N}=1069) .{ }^{59}$ However, no statistically significant differences in overall survival, bone metastasis-free survival, or nonskeletal metastasis-free survival were seen when a meta-analysis of this and subsequent clodronate trials in the adjuvant setting was conducted $(\mathrm{N}=1653) .{ }^{60}$ Nonetheless, other phase III trials of bisphosphonates for early breast cancer are underway.

The possible mechanisms behind the antitumor effects of zoledronic acid may be provided in part by much of the preclinical study data demonstrating the antitumor properties of zoledronic acid including induction of tumor cell apoptosis, inhibition of tumor angiogenesis, immune cell activation, and decreased adhesion of tumor cells to bone (Figure 1). ${ }^{29,39,61-64}$ Although the antitumor effects observed for in vitro and in vivo preclinical studies are very clear, the question that remains is how a compound that preferentially binds to bone exerts such broad-reaching antitumor effects in the clinic. A hypothesis proposed in 1889 by Stephen Paget that the bone microenvironment influences tumor growth ("seed and soil" hypothesis) may offer a partial explanation for improved DFS in zoledronic acid-treated patients. In the Z-FAST, ZO-FAST, and E-ZO-FAST trials, and in the bone substudy of ABCSG-12 in the adjuvant therapy setting, 9,25,26,57 zoledronic acid ( $4 \mathrm{mg}$ every 6 months) effectively prevented AIBL, possibly rendering the bone microenvironment a less favorable "soil" for tumor growth. This idea is borne out by 4 phase I trials $(\mathrm{N}=435)$ demonstrating that zoledronic acidtreated breast cancer patients had reduced micrometastases in their bone marrow. ${ }^{65-68}$ For example, in 1 study $(\mathrm{N}=45)$, zoledronic acid ( $4 \mathrm{mg}$ monthly) significantly reduced the mean number of tumor cells in bone marrow at 24 months ( $p=0.0026$ ), with reductions in $71 \%$ of patients. ${ }^{66}$ According to the seed-and-soil hypothesis, zoledronic acid in bone may thereby limit the future seeding of tumor cells to more distant sites. Because there appears to be a significant correlation between tumor cells in bone marrow and the risk of distant relapse, ${ }^{69}$ the idea that reducing or eliminating bone marrow micrometastases will prevent distant disease recurrence seems plausible. However, further studies will be needed to define the precise antitumor mechanisms involved in the adjuvant therapy setting.

In summary, zoledronic acid has demonstrated considerable efficacy for preventing CTIBL in patients with early breast cancer. Additional evidence from some of these clinical trials indicates that adding zoledronic acid to adjuvant endocrine therapy can significantly improve DFS beyond what is achieved with endocrine therapy alone. Because of the favorable side-effect profile of zoledronic acid in the adjuvant setting and the significant bone health and survival benefits achieved, it is likely that zoledronic acid may become part of standard adjuvant therapy for early breast cancer. Although this review has focused on results from trials of zoledronic acid in patients with early breast cancer, several ongoing phase III clinical studies are examining the efficacy of zoledronic acid for preventing bone metastases in breast, lung, prostate, and other cancers (eg, AZURE, SUCCESS, NATAN, SWOG 0307, NSABP B-34, AZAC, study 2419, ZEUS, STAMPEDE, and RADAR). Results from these ongoing studies will likely continue to shape the role of zoledronic acid in the early cancer settings.

\section{Acknowledgments}

Financial support for medical editorial assistance was provided by Novartis Pharmaceuticals. I thank Michael Hobert, $\mathrm{PhD}$, for his medical editorial assistance with this manuscript.

\section{Disclosures}

Michael Gnant has received research support from and/or served as a consultant for AstraZeneca, Novartis, and Pfizer, and has received lecture fees and honoraria for participation in advisory boards from AstraZeneca, Novartis, sanofi-aventis, Roche, Schering, Amgen, and Pfizer.

\section{References}

1. American Cancer Society. Breast cancer facts and figures 2007-2008. Atlanta: American Cancer Society, Inc; 2007.

2. Chen Z, Maricic M, Bassford TL, et al. Fracture risk among breast cancer survivors: results from the Women's Health Initiative Observational Study. Arch Intern Med. 2005;165(5):552-558.

3. Chen Z, Maricic M, Pettinger M, et al. Osteoporosis and rate of bone loss among postmenopausal survivors of breast cancer. Results from a subgroup in the Women's Health Initiative Observational Study. Cancer. 2005;104(7):1520-1530.

4. Greep NC, Giuliano AE, Hansen NM, Taketani T, Wang H-J, Singer FR. The effects of adjuvant chemotherapy on bone density in postmenopausal women with early breast cancer. Am J Med. 2003;114(8): 653-659.

5. Shapiro CL, Manola J, Leboff M. Ovarian failure after adjuvant chemotherapy is associated with rapid bone loss in women with earlystage breast cancer. J Clin Oncol. 2001;19(14):3306-3311. 
6. Li CI, Daling JR, Malone KE. Incidence of invasive breast cancer by hormone receptor status from 1992 to 1998. J Clin Oncol. 2003;21(1):28-34

7. Coombes RC, Kilburn LS, Snowdon CF, et al. Survival and safety of exemestane versus tamoxifen after 2-3 years' tamoxifen treatment (Intergroup Exemestane Study): a randomised controlled trial. Lancet. 2007;369(9561):559-570.

8. Eastell R, Hannon RA, Cuzick J, Dowsett M, Clack G, Adams JE. Effect of an aromatase inhibitor on BMD and bone turnover markers: 2-year results of the Anastrozole, Tamoxifen, Alone or in Combination (ATAC) trial (18233230). J Bone Miner Res. 2006;21(8):1215-1223.

9. Gnant M, Mlineritsch B, Luschin-Ebengreuth G, et al. Adjuvant endocrine therapy plus zoledronic acid in premenopausal women with early-stage breast cancer: 5-year follow-up of the ABCSG-12 bonemineral density substudy. Lancet Oncol. 2008;9(9):840-849.

10. Howell A, Cuzick J, Baum M, et al. Results of the ATAC (Arimidex, Tamoxifen, Alone or in Combination) trial after completion of 5 years' adjuvant treatment for breast cancer. Lancet. 2005;365(9453):60-62.

11. Jakesz R, Jonat W, Gnant M, et al. Switching of postmenopausal women with endocrine-responsive early breast cancer to anastrozole after 2 years' adjuvant tamoxifen: combined results of ABCSG trial 8 and ARNO 95 trial. Lancet. 2005;366(9484):455-462.

12. Thurlimann B, Keshaviah A, Coates AS, et al. A comparison of letrozole and tamoxifen in postmenopausal women with early breast cancer N Engl J Med. 2005;353(26):2747-2757.

13. Eastell R, Adams JE, Coleman RE, et al. Effect of anastrozole on bone mineral density: 5-year results from the anastrozole, tamoxifen, alone or in combination trial 18233230. J Clin Oncol. 2008;26(7): 1051-1058.

14. Coleman RE, Banks LM, Girgis SI, et al. Skeletal effects of exemestane on bone-mineral density, bone biomarkers, and fracture incidence in postmenopausal women with early breast cancer participating in the Intergroup Exemestane Study (IES): a randomised controlled study. Lancet Oncol. 2007;8(2):119-127.

15. World Health Organization. WHO technical report series 921 : prevention and management of osteoporosis. Geneva, Switzerland: World Health Organization; 2003:1-192. http://whqlibdoc.who.int. trs/WHO_TRS_921.pdf.

16. National Osteoporosis Foundation. Clinician's guide to prevention and treatment of osteoporosis. Available at: www.nof.org. Accessed December 18, 2008.

17. Hillner BE, Ingle JN, Chlebowski RT, et al. American Society of Clinical Oncology 2003 update on the role of bisphosphonates and bone health issues in women with breast cancer. J Clin Oncol. 2003;21(21):4042-4057.

18. Kanis JA. FRAX ${ }^{\circledR}$ WHO fracture risk assessment tool. Sheffield, UK: World Health Organization Collaborating Centre for Metabolic Bone Diseases, University of Sheffield. http://www.shef.ac.uk/FRAX/index.htm.

19. Aapro M, Abrahamsson PA, Body JJ, et al. Guidance on the use of bisphosphonates in solid tumours: recommendations of an international expert panel. Ann Oncol. 2008;19(3):420-432.

20. Hadji P, Body JJ, Aapro MS, et al. Practical guidance for the management of aromatase inhibitor-associated bone loss. Ann Oncol. 2008;19(8):1407-1416.

21. Vehmanen L, Saarto T, Elomaa I, Makela P, Valimaki M, Blomqvist C. Long-term impact of chemotherapy-induced ovarian failure on bone mineral density (BMD) in premenopausal breast cancer patients. The effect of adjuvant clodronate treatment. Eur J Cancer. 2001;37(18): 2373-2378.

22. Lester JE, Dodwell D, Purohit OP, et al. Prevention of anastrozoleinduced bone loss with monthly oral ibandronate during adjuvant aromatase inhibitor therapy for breast cancer. Clin Cancer Res. 2008;14(19):6336-6342.

23. Van Poznak C, Hannon RA, Clack G, et al. The SABRE (Study of Anastrozole with the Bisphosphonate RisedronatE) study: 12-month analysis [abstract]. Breast Cancer Res Treat. 2007;106(suppl 1):S37. Abstract 502.
24. Brufsky A, Bundred N, Coleman R, et al. Integrated analysis of zoledronic acid for prevention of aromatase inhibitor-associated bone loss in postmenopausal women with early breast cancer receiving adjuvant letrozole. Oncologist. 2008;13(5):503-514.

25. Bundred NJ, Campbell ID, Davidson N, et al. Effective inhibition of aromatase inhibitor-associated bone loss by zoledronic acid in postmenopausal women with early breast cancer receiving adjuvant letrozole: ZO-FAST study results. Cancer. 2008;112(5):1001-1010.

26. Schenk N, Lombart A, Frassoladti A, et al. The E-ZO-FAST trial: zoledronic acid (ZA) effectively inhibits aromatase inhibitor associated bone loss (AIBL) in postmenopausal women (PMW) with early breast cancer (EBC) receiving adjuvant letrozole (Let) [abstract]. Eur J Cancer Suppl. 2007;5(4 suppl):186-187. Abstract 2008.

27. Coxon JP, Oades GM, Kirby RS, Colston KW. Zoledronic acid induces apoptosis and inhibits adhesion to mineralized matrix in prostate cancer cells via inhibition of protein prenylation. BJU Int. 2004;94(1): 164-170.

28. Croucher PI, De Raeve H, Perry MJ, et al. Zoledronic acid treatment of 5T2MM-bearing mice inhibits the development of myeloma bone disease: evidence for decreased osteolysis, tumor burden and angiogenesis, and increased survival. J Bone Miner Res. 2003;18(3):482-492.

29. Daubine F, Le Gall C, Gasser J, Green J, Clezardin P. Antitumor effects of clinical dosing regimens of bisphosphonates in experimental breast cancer bone metastasis. J Natl Cancer Inst. 2007;99(4):322-330.

30. Duivenvoorden WC, Vukmirovic-Popovic S, Kalina M, Seidlitz E, Singh G. Effect of zoledronic acid on the doxycycline-induced decrease in tumour burden in a bone metastasis model of human breast cancer. Br J Cancer. 2007;96(10):1526-1531.

31. Fiore F, Castella B, Nuschak B, et al. Enhanced ability of dendritic cells to stimulate innate and adaptive immunity upon short-term incubation with zoledronic acid. Blood. 2007;110(3):921-927.

32. Fournier P, Boissier S, Filleur S, et al. Bisphosphonates inhibit angiogenesis in vitro and testosterone-stimulated vascular regrowth in the ventral prostate in castrated rats. Cancer Res. 2002;62(22): 6538-6544.

33. Hiraga T, Williams PJ, Ueda A, Tamura D, Yoneda T. Zoledronic acid inhibits visceral metastases in the 4T1/luc mouse breast cancer model. Clin Cancer Res. 2004;10(13):4559-4567.

34. Jagdev SP, Coleman RE, Shipman CM, Rostami-H A, Croucher PI. The bisphosphonate, zoledronic acid, induces apoptosis of breast cancer cells: evidence for synergy with paclitaxel. $\mathrm{Br} J$ Cancer. 2001;84(8):1126-1134.

35. Neville-Webbe HL, Evans CA, Coleman RE, Holen I. Mechanisms of the synergistic interaction between the bisphosphonate zoledronic acid and the chemotherapy agent paclitaxel in breast cancer cells in vitro. Tumour Biol. 2006;27(2):92-103.

36. Neville-Webbe HL, Rostami-Hodjegan A, Evans CA, Coleman RE, Holen I. Sequence- and schedule-dependent enhancement of zoledronic acid induced apoptosis by doxorubicin in breast and prostate cancer cells. Int J Cancer. 2005;113(3):364-371.

37. Ottewell PD, Monkkonen H, Jones M, Lefley DV, Coleman RE, Holen I. Antitumor effects of doxorubicin followed by zoledronic acid in a mouse model of breast cancer. J Natl Cancer Inst. 2008;100(16): 1167-1178.

38. Ottewell PD, Deux B, Monkkonen H, et al. Differential effect of doxorubicin and zoledronic acid on intraosseous versus extraosseous breast tumor growth in vivo. Clin Cancer Res. 2008;14(14):4658-4666.

39. Mundy GR. Metastasis to bone: causes, consequences and therapeutic opportunities. Nat Rev Cancer. 2002;2(8):584-593.

40. Siris ES, Chen YT, Abbott TA, et al. Bone mineral density thresholds for pharmacological intervention to prevent fractures. Arch Intern Med. 2004;164(10):1108-1112.

41. Kanis JA, Borgstrom F, De Laet C, et al. Assessment of fracture risk. Osteoporos Int. 2005;16(6):581-589.

42. Black DM, Delmas PD, Eastell R, et al. Once-yearly zoledronic acid for treatment of postmenopausal osteoporosis. $N$ Engl J Med. 2007;356(18):1809-1822. 
43. Rosen LS, Gordon D, Kaminski M, et al. Zoledronic acid versus pamidronate in the treatment of skeletal metastases in patients with breast cancer or osteolytic lesions of multiple myeloma: a phase III, double-blind, comparative trial. Cancer J. 2001;7(5):377-387.

44. Gnant MFX, Mlineritsch B, Luschin-Ebengreuth G, et al. Zoledronic acid prevents cancer treatment-induced bone loss in premenopausal women receiving adjuvant endocrine therapy for hormone-responsive breast cancer: a report from the Austrian Breast and Colorectal Cancer Study Group. J Clin Oncol. 2007;25(7):820-828.

45. Brufsky A, Bosserman L, Caradonna R, et al. Zoledronic acid (ZA) prevents aromatase inhibitor (AI)-associated bone loss in postmenopausal women with early breast cancer: 36-month follow-up of the Z-FAST study [poster]. Presented at: 6th European Breast Cancer Conference; April 15-19, 2008; Berlin, Germany. Abstract 494.

46. Eidtmann H, Bundred N, De Boer R, et al. The effect of zoledronic acid on aromatase inhibitor associated bone loss in postmenopausal women with early breast cancer receiving letrozole: 36 months follow-up of ZO-FAST. Presented at: 31 st San Antonio Breast Cancer Symposium; December 10-14, 2008; San Antonio, TX. Abstract 44.

47. Aft R, Chavez-MacGregor M, Trinkaus K, Naughton M, Weilbaecher K. Effect of zoledronic acid on bone loss in women undergoing chemotherapy for breast cancer [abstract]. Breast Cancer Res Treat. 2007; 106(suppl 1):S38. Abstract 505.

48. Hershman DL, McMahon DJ, Crew KD, et al. Zoledronic acid prevents bone loss in premenopausal women undergoing adjuvant chemotherapy for early-stage breast cancer. J Clin Oncol. 2008;26(29):4739-4745.

49. Gnant M, Mlineritsch B, Schippinger W, et al. Endocrine therapy plus zoledronic acid in premenopausal breast cancer. $N$ Engl J Med.

50. Frassoldati A, Brufsky A, Bundred N, et al. The effect of zoledronic acid on aromatase inhibitor (AI) associated bone loss (AIBL) in postmenopausal women (PMW) with early breast cancer (EBC) receiving adjuvant letrozole: 24 months (mos) integrated follow-up of the Z-FAST/ ZO-FAST trials. Ann Oncol. 2008;19(suppl 8):viii78. Abstract 185PD.

51. Khosla S, Burr D, Cauley J, et al. Bisphosphonate-associated osteonecrosis of the jaw: report of a task force of the American Society for Bone and Mineral Research. J Bone Miner Res. 2007;22(10):1479-1491.

52. Weitzman R, Sauter N, Eriksen EF, et al. Critical review: updated recommendations for the prevention, diagnosis, and treatment of osteonecrosis of the jaw in cancer patients - May 2006. Crit Rev Oncol Hematol. 2007;62(2):148-152.

53. Pavlakis N, Schmidt RL, Stockler M. Bisphosphonates for breast cancer. Cochrane Database Syst Rev. 2003(3):CD003474. DOI: 10.1002/14651858.CD003474.pub2.

54. Lipton A, Theriault RL, Hortobagyi GN, et al. Pamidronate prevents skeletal complications and is effective palliative treatment in women with breast carcinoma and osteolytic bone metastases: long term follow-up of two randomized, placebo-controlled trials. Cancer. 2000;88(5):1082-1090.

55. Body JJ, Diel IJ, Lichinitser MR, et al. Intravenous ibandronate reduces the incidence of skeletal complications in patients with breast cancer and bone metastases. Ann Oncol. 2003;14(9):1399-1405. 2009;360(7):679-691.

56. Kohno N, Aogi K, Minami H, et al. Zoledronic acid significantly reduces skeletal complications compared with placebo in Japanese women with bone metastases from breast cancer: a randomized, placebo-controlled trial. J Clin Oncol. 2005;23(15):3314-3321.

57. Brufsky A, Harker WG, Beck JT, et al. Zoledronic acid inhibits adjuvant letrozole-induced bone loss in postmenopausal women with early breast cancer. J Clin Oncol. 2007;25(7):829-836.

58. Diel IJ, Solomayer EF, Costa SD, et al. Reduction in new metastases in breast cancer with adjuvant clodronate treatment. $N$ Engl J Med. 1998;339(6):357-363.

59. Powles T, Paterson A, McCloskey E, et al. Reduction in bone relapse and improved survival with oral clodronate for adjuvant treatment of operable breast cancer [ISRCTN83688026]. Breast Cancer Res. 2006;8(2):R13.

60. Ha TC, Li H. Meta-analysis of clodronate and breast cancer survival. Br J Cancer. 2007;96(12):1796-1801.

61. Aviles A, Nambo MJ, Neri N, Castaneda C, Cleto S, Huerta-Guzman J. Antitumor effect of zoledronic acid in previously untreated patients with multiple myeloma. Med Oncol. 2007;24(2):227-230.

62. Mystakidou K, Katsouda E, Parpa E, Kelekis A, Galanos A, Vlahos L. Randomized, open label, prospective study on the effect of zoledronic acid on the prevention of bone metastases in patients with recurrent solid tumors that did not present with bone metastases at baseline. Med Oncol. 2005;22(2):195-201.

63. Santini D, Martini F, Fratto ME, et al. In vivo effects of zoledronic acid on peripheral gammadelta $\mathrm{T}$ lymphocytes in early breast cancer patients. Cancer Immunol Immunother. 2009;58(1):31-38.

64. Santini D, Vincenzi B, Galluzzo S, et al. Repeated intermittent low-dose therapy with zoledronic acid induces an early, sustained, and long-lasting decrease of peripheral vascular endothelial growth factor levels in cancer patients. Clin Cancer Res. 2007;13(15 pt 1): 4482-4486.

65. Aft R, Watson M, Ylagan L, et al. Effect of zoledronic acid on bone marrow micrometastases in women undergoing neoadjuvant chemotherapy for breast cancer. J Clin Oncol. 2008;26(15 suppl):46s. Abstract 1021.

66. Lin AY, Park JW, Scott J, et al. Zoledronic acid as adjuvant therapy for women with early stage breast cancer and disseminated tumor cells in bone marrow [abstract]. J Clin Oncol. 2008;26(15 suppl):20s. Abstract 559.

67. Rack BK, Jueckstock J, Genss EM, et al. Effect of zoledronate on persisting isolated tumor cells in the bone marrow of patients without recurrence of early breast cancer [abstract]. Breast Cancer Res Treat. 2007;106(suppl 1):S40. Abstract 511.

68. Solomayer EF, Gebauer G, Hirnle P, et al. Influence of zoledronic acid on disseminated tumor cells (DTC) in primary breast cancer patients. Cancer Res. 2009;69(suppl 2):170s. Abstract 2048.

69. Braun S, Vogl FD, Naume B, et al. A pooled analysis of bone marrow micrometastasis in breast cancer. $N$ Engl J Med. 2005;353(8): 793-802.

\section{Dovepress}

\section{Publish your work in this journal}

OncoTargets and Therapy is an international, peer-reviewed, open access journal focusing on the pathological basis of all cancers, potential targets for therapy and treatment protocols employed to improve the management of cancer patients. The journal also focuses on the impact of management programs and new therapeutic agents and protocols on

Submit your manuscript here: http://www.dovepress.com/oncotargets-and-therapy-journal patient perspectives such as quality of life, adherence and satisfaction. The manuscript management system is completely online and includes a very quick and fair peer-review system, which is all easy to use. Visit http://www.dovepress.com/testimonials.php to read real quotes from published authors. 